\title{
Mapping and Characterizing Displacements of Landslides with InSAR and Airborne LiDAR Technologies: A Case Study of Danba County, Southwest China
}

\author{
Qiang Xu, Chen Guo *, Xiujun Dong, Weile Li D, Huiyan Lu, Hao Fu and Xiaosha Liu \\ State Key Laboratory of Geohazard Prevention and Geoenvironment Protection, Chengdu University of \\ Technology, Chengdu 610059, China; xq@cdut.edu.cn (Q.X.); dongxiujun@cdut.cn (X.D.); \\ liweile08@mail.cdut.edu.cn (W.L.); 2017050002@stu.cdut.edu.cn (H.L.); 2019020030@stu.cdut.edu.cn (H.F.); \\ 1xs@stu.cdut.edu.cn (X.L.) \\ * Correspondence: gc@stu.cdut.edu.cn
}

\section{check for} updates

Citation: Xu, Q.; Guo, C.; Dong, X.; Li, W.; Lu, H.; Fu, H.; Liu, X. Mapping and Characterizing Displacements of Landslides with InSAR and Airborne LiDAR Technologies: A Case Study of Danba County, Southwest China. Remote Sens. 2021, 13, 4234 https://doi.org/10.3390/ rs13214234

Academic Editors: Ali Khenchaf and Jean-Christophe Cexus

Received: 14 September 2021

Accepted: 13 October 2021

Published: 21 October 2021

Publisher's Note: MDPI stays neutral with regard to jurisdictional claims in published maps and institutional affiliations.

Copyright: (c) 2021 by the authors. Licensee MDPI, Basel, Switzerland. This article is an open access article distributed under the terms and conditions of the Creative Commons Attribution (CC BY) license (https:// creativecommons.org/licenses/by/ $4.0 /)$.

\begin{abstract}
Interferometric synthetic aperture radar (InSAR) technology is known as one of the most effective methods for active landslide identification and deformation monitoring in large areas, and thus it is conducive to preventing and mitigating the losses caused by landslides. However, great uncertainty inevitably exists due to influences of complex terrains, dense vegetations, and atmospheric interferences in the southwestern mountainous area of China, and this is associated with false or erroneous judgment during the process of landslide identification. In this study, a landslide identification method is put forward by integrating InSAR technology and airborne light detection and ranging (LiDAR) technology. Via this method, surface deformation characteristics detected by InSAR technology and micro-geomorphic features reflected by LiDAR technology were used to identify and map landslides of large areas. Herein, the method was applied to process 224 Sentinel-1 images covering Danba County and its surrounding areas $\left(540 \mathrm{~km}^{2}\right)$ from October 2014 to September 2020. Firstly, 44 active landslides with total areas of $59 \mathrm{~km}^{2}$ were detected by stacking InSAR technology. Then, major regions up to $135 \mathrm{~km}^{2}$ were validated by data gained from the airborne LiDAR technology. Particularly, several large landslides with lengths and/or widths of more than $2 \mathrm{~km}$ were found. Further, the precipitation data were integrated with the above results to analyze the temporal deformation characteristics of three typical landslides from major regions via SBAS InSAR technology. The key findings were as follows: (1) The combination of InSAR and LiDAR technologies could improve the accuracy of landslide detection and identification; (2) there was a significant correlation between temporal deformation characteristics of some landslides and monthly rainfall, with an obvious hysteretic effect existing between the initiation timing of rainfall and that of deformation; (3) the results of this study will be important guidance for the prevention and control of geological hazards in Danba County and areas with similar complex geomorphological conditions by helping effectively identify and map landslides.
\end{abstract}

Keywords: landslide detection; deformation monitoring; time series InSAR analysis; airborne LiDAR; high resolution DEM; rainfall

\section{Introduction}

Affected by the recent continuous uplift of the Qinghai-Tibet Plateau, western China, especially the east side of the Qinghai-Tibet Plateau, features deep rivers, complex topography and geological conditions, and frequently occurring geological hazards such as collapses, landslides, and debris flow [1]. The ever-increasing occurrences of large catastrophic landslides in recent years have caused great social impact and huge economic and property losses [2,3], including the landslide in Xinmo Village, Maoxian County in 2017 [4]; the avalanche, landslide, and river-blocking dam of the Yarlung Zangbo River in Tibet during 2018 [5]; and the Baige landslide in the Jinsha River in 2019 [6]. Geological 
hazards in these areas are often concealed, harmful, and difficult to prevent due to the high altitude, steep terrain, and dense vegetation. Therefore, it is of great importance to identify and monitor the displacement of landslides in these mountainous and canyon areas with complex terrain in western China to protect the safety of human life and infrastructure [7].

In addition to traditional ground surveys, aerospace remote-sensing technologies such as optical remote sensing [8,9], airborne light detection and ranging (LiDAR), unmanned aerial vehicles (UAVs) [10,11], and interferometric synthetic aperture radar (InSAR) [12-14] have gradually become the main technical means for landslide identification and displacement monitoring. However, satellite and UAV optical imaging cannot accurately measure the displacement of landslides, while airborne LiDAR is very expensive and thus not suitable for landslide identification in a large area. In contrast, the InSAR technology is favored due to its capacity to detect small surface deformations at all times in all weather conditions with high resolution. Therefore, it has become the first choice for landslide identification and deformation monitoring. In 1994, Fruneau first proved the effectiveness of DInSAR in landslide monitoring [15], and follow-up work has been successively carried out on the application of DInSAR technology in landslide detection and monitoring [16,17]. Gradually, an increasing number of methods have been developed and widely used in large-area landslide identification and displacement monitoring, including SBAS-InSAR [18], PS-InSAR [19,20], and SquessSAR [21], which benefited from the development of SAR sensors, the continuous accumulation of SAR images, and the advancement of science and technology.

Landslide identification in large areas based on different InSAR methods has been carried out in the Three Gorges area [16], the Bailong River Basin [22], the Jinsha River Basin [23,24], the Yalong River Basin [25], and other mountainous areas in western China. However, these mountainous areas with steep undulations and dense vegetation can inevitably result in the geometric distortion of SAR images [26] and problems with volume and/or temporal decorrelation. The combined effect of these factors will increase the uncertainty of deformation measurement, which will increase the possibility of false or erroneous judgment in landslide identification and mapping. Therefore, when verification is absent, the reliability of InSAR identification and monitoring results are compromised to a certain extent.

As an emerging remote-sensing technology, airborne LiDAR can obtain three-dimensional, dense, real-point cloud data. After filtering and removing vegetation, a high-resolution digital elevation model (DEM) can be obtained, which can well reflect the real micro-geomorphic features under the vegetation cover to reveal the morphological features of the hidden landslides. In recent years, high-resolution digital imagery and elevation datasets have become much easier to acquire, owing to the rapid progress of science and technology, which has allowed researchers to map smaller and more subtle slope failure events. Airborne LiDAR has been widely used in landslide investigations, and it is especially suitable for mapping the landslides covered by dense vegetation [11,27-29]. In this study, high-resolution DEM and its derivatives were used to verify the landslide detection results of InSAR by means of remote sensing, and they could also help accurately characterize the boundary of the landslide according to the geomorphological features.

In this study, InSAR and airborne LiDAR technologies were integrated to identify and map landslides in Danba County and the surrounding areas, accompanied by a new procedure for landslide identification and deformation monitoring. The aims of this study were: (1) To use stacking InSAR technology to detect landslides in a large area, and then use LiDAR data to validate the InSAR detection results in a smaller area, and eventually improve the accuracy and reliability of landslide identification in the complex mountainous areas with dense vegetation cover; and (2) to analyze the time-series deformation characteristics of typical landslides based on high-precision LiDAR-DEM and rainfall data. 


\section{Methodology}

The steep terrain and dense vegetation in the mountainous areas of western China increase the uncertainty of InSAR deformation measurements [30]. Therefore, the lack of effective verification may affect the reliability of the landslide identification results to a certain extent. In this study, efforts were first made to detect active landslides via the stacking InSAR technology in a large area. Subsequently, airborne LiDAR data were employed to verify, modify, and accurately draw the boundaries of active landslides by observing the micro-geomorphic features in the high-resolution DEM in a smaller area. Finally, SBAS-InSAR was applied to analyze the historical deformation characteristics of typical landslides to improve the reliability of the InSAR measurement results. A detailed workflow is shown in Figure 1.

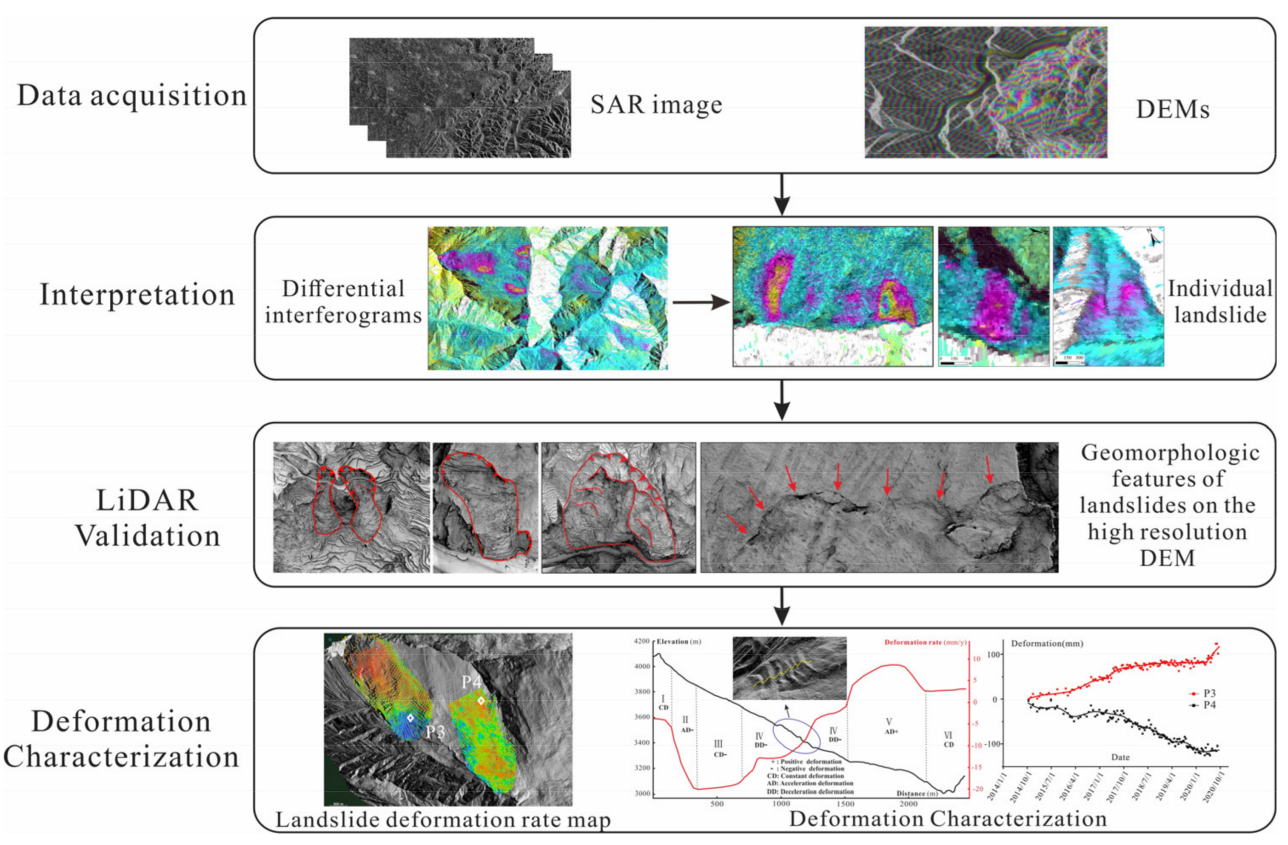

Figure 1. The adopted workflow for mapping and characterizing landslides in a large area.

\subsection{Stacking InSAR and SBAS InSAR Technology}

Stacking InSAR technology was developed based on conventional DInSAR technology, and it can improve the relative accuracy of deformation information from atmospheric disturbances through linear superposition of multiple differential interferograms [31]. The basic assumption of stacking InSAR technology is that the phase of atmospheric disturbances are random in time, while the ground deformation signal is time-dependent and can be approximately regarded to change linearly with time. It is feasible to suppress the atmospheric-disturbance phase by superimposing the corresponding unwrapping phases of multiple differential interferograms at different times, thereby improving the measurement accuracy of the deformation phase. This method can only obtain the relative deformation of the landslide in a certain period of time, and thus it cannot reflect the temporal evolution of the landslide. However, it also has certain advantages, since it does not require many complicated calculations, thereby contributing to the quick and efficient detection of small ground deformation. Accordingly, it has been widely used to quickly identify hidden dangers of landslides in a large area.

SBAS-InSAR technology is a time-series InSAR processing method based on multimaster images, which can better overcome the effects of spatiotemporal decoherence and extract the effective information of distributed scatterers as much as possible, thereby improving the reliability and accuracy of deformation measurement results [18]. The basic principle is as follows: (1) Conventional DInSAR processing is performed on the $M$ interferometric pairs obtained from multiperiod SAR images according to a certain 
spatiotemporal baseline threshold, including differential interference, filtering, and unwrapping; (2) modeling and calculation of low-frequency deformation and elevation errors are implemented based on the unwrapping phase; (3) low-frequency deformation and elevation errors are removed from the original differential interferogram, followed by wrapping on the residual differential interference phase and unwrapping to obtain the high-frequency deformation phase; (4) this high-frequency deformation phase is then added to the previous low-frequency deformation phase, the results of which are subjected to low-pass filtering in the space domain and high-pass filtering in the time domain to remove atmospheric errors; and (5) finally, the singular value decomposition is used to obtain the least-norm least square solution of the deformation rate, accompanied by the acquirement of the time-series deformation of the entire time period by integration in the time domain.

SBAS-InSAR technology can overcome the defects of stacking InSAR technology to a certain extent, thereby improving the accuracy of landslide deformation measurement and helping obtain the temporal and spatial characteristics of landslide evolution. However, SBAS-InSAR technology requires extensive image data accumulation in the target area, and data processing in large areas is complicated and inefficient. Therefore, it is logical to combine stacking InSAR and SBAS-InSAR by first detecting and identifying landslides in a large area with stacking InSAR and then monitoring time-series deformation of landslides in key areas with SBAS-InSAR. In this way, it is more efficient to perform landslide detection and identification, as well as deformation monitoring.

\subsection{Airborne LiDAR}

Airborne LiDAR uses a manned or unmanned aerial vehicle as the carrying platform, and it can accurately obtain the spatial coordinates of the target point through an integrated attitude positioning system and a laser scanner that actively emits a laser beam. Moreover, the acquired point cloud data can be combined with the corresponding filtering algorithm to effectively remove surface vegetation, buildings, and other undesired objects to obtain the real DEM. Then, the high-resolution DEM and its derivatives can be utilized to reflect the real micro-geomorphic features. In this context, it is feasible to effectively identify and map historical landslides according to the morphologies of fractures, hummocks, pressure ridges, and depressions on the surface during the deformation and movement of the landslides. LiDAR applications have achieved great success in recent years in mapping landslide morphology and estimating landslide activity in areas partially or completely covered by dense vegetation [32-34].

\section{Study Area and Datasets}

\subsection{Study Area}

The study area was located in Danba County, in the northeastern Ganzi Tibetan Autonomous Prefecture, Sichuan Province, Southwest China (Figure 2a). It was about $400 \mathrm{~km}$ from Chengdu, the capital city of Sichuan. The elevation difference in the study area was $3000 \mathrm{~m}$, with an average altitude of about $3200 \mathrm{~m}$, At the same time, there were abundant plant resources and dense vegetation cover in the study area, which indicated a typical erosion-denudation-dominated high mountain-gorge landform. Geologically, this area exposes silver-gray quartz-mica schist, the Fourth Formation-complex ( $\left.\mathrm{Smx}{ }^{4}\right)$ of the Maoxian group, and the Silurian system; and the overburden material consists of old landslide debris $\left(\mathrm{Q}_{4}{ }^{\mathrm{del}}\right)$ and rock-fall deposits $\left(\mathrm{Q}_{4}{ }^{\mathrm{col}+\mathrm{dl}}\right)$. The NE-SW Xiaojin River and the N-S Dajinchuan River flow through the study area, and converge into the Dadu River after flowing through Danba County, and this area is characterized by heavy erosion by the river (Figure $2 \mathrm{~b}$ ). The precipitation in the study area has uneven distribution throughout the year, and the mean annual and monthly precipitation are about $668 \mathrm{~mm}$ and $55 \mathrm{~mm}$, respectively. The monthly precipitation peaks in June and September and the average rainfall in June and September are about $160 \mathrm{~mm}$ and $97 \mathrm{~mm}$, respectively. The amount of daily precipitation is large during the flood season, and is very likely to trigger geological hazards. 


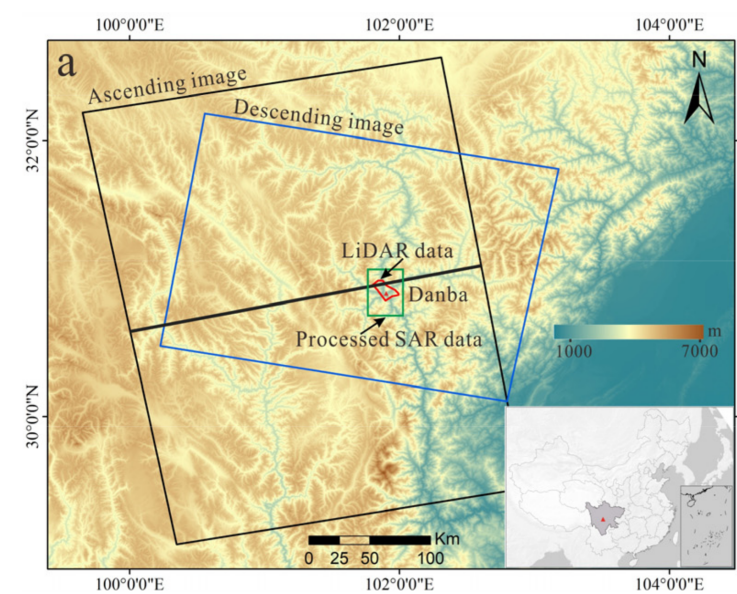

(a)

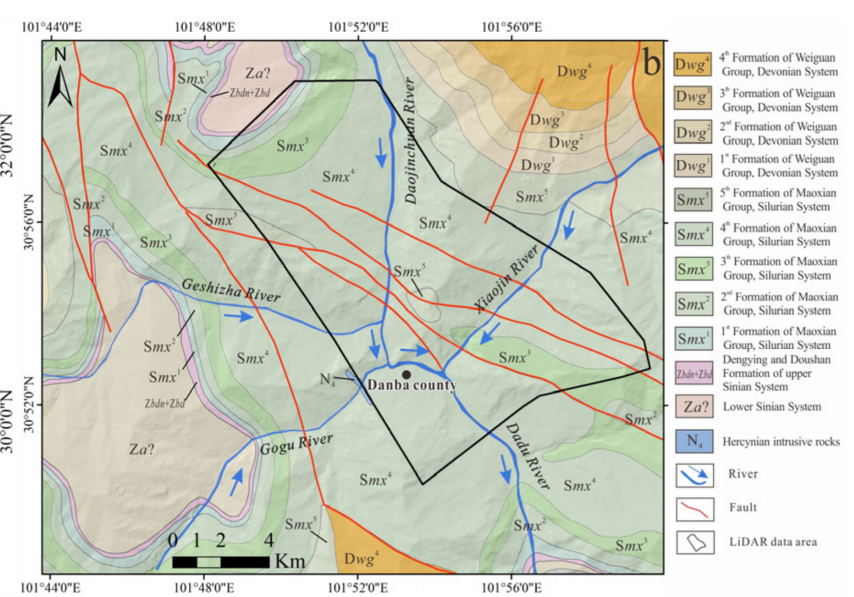

(b)

Figure 2. (a) Location of Danba County and coverage of the SAR datasets; (b) tectonic and geological map of the study area.

Physiographically, the study area is located in the eastern part of the Qinghai-Tibet Plateau; has a prolonged geological history, complex structure system, and fragile geological environment; is characterized by neotectonic movements; and has frequent occurrences of geological hazards. Therefore, the area has been graded as a high-susceptibility zone of geological hazards in Sichuan Provence. With the continuously expanding human activity, the development of geological hazards in Danba County tends to grow, and multiple landslide deformations are reactivated, which brings about major threats to the life and property security of local residents. For example, The June. 26 and July. 11 debris flow disasters in 2003 caused severe casualties (50 missing and 1 dead, and 7 missing and 10 dead, respectively) and huge financial losses. In February 2005, the Jianshe Road landslide in the county reactivated and imperiled the safety of half of the county. This aroused concerns of the state and the Sichuan government, which actively dealt with the emergency and spent tens of millions of RMB on emergency rescues and comprehensive treatment. Geological hazards have severely threatened the economic development, social security, and local prosperity of Danba County.

\subsection{SAR Data}

The deformation rate along the line of sight (LOS) in the study area was estimated based on 134 Sentinel-1 ascending images and 90 descending images from October 2014 to December 2020 (Table 1). Meanwhile, an SRTM DEM with a resolution of $30 \mathrm{~m}$ was used as the reference elevation data to remove the terrain phase component from the interferogram. GAMMA software of Switzerland was used for stacking and SBAS InSAR data processing; the images from 21 December 2018 and 28 December 2018 were selected as the primary images for the ascending and descending orbit data, respectively. The temporal and spatial baseline threshold of ascending data were $192 \mathrm{~d}$ and $203 \mathrm{~m}$, respectively. Due to the lack of descending images from March 2017 to March 2018, the threshold of descending orbit data was set at a temporal baseline of $462 \mathrm{~d}$ and a spatial baseline of $180 \mathrm{~m}$, which resulted in 655 groups and 435 groups of interference pairs, respectively. As the study area was located in a mountainous area, the threshold was set to 0.2 in order to obtain more coherent points. 
Table 1. The basic parameters of the SAR datasets.

\begin{tabular}{ccc}
\hline Sensor & Sentinel-1A & Sentinel-1A \\
\hline Orbit direction & Ascending & Descending \\
Wavelength $(\mathrm{cm})$ & 5.6 & 5.6 \\
Resolution $(\mathrm{m})$ & $5 \times 20$ & $5 \times 20$ \\
Repeat cycle $(\mathrm{d})$ & 12 & 12 \\
Polarization & $\mathrm{VV}$ & $\mathrm{VV}$ \\
Look angle $\left({ }^{\circ}\right)$ & $20 \sim 45^{\circ}$ & $20 \sim 45^{\circ}$ \\
Temporal coverage & October 2014 September 2020 & October 2014 September 2020 \\
Number of images & 134 & 90 \\
\hline
\end{tabular}

\subsection{Airborne LiDAR Data}

In this work, the airborne LiDAR data covered an area of about $135 \mathrm{~km}^{2}$ around Danba County, accounting for about $1 / 4$ of the InSAR detection area. The LiDAR data were acquired during the period of 13 February2019 to 19 February 2019. During the data acquisition, an AS350 helicopter was equipped with a SKYEYE SE-J1200B airborne LiDAR system that was applied to areas of high mountains and hills; is the system was manufactured by Mianyang Skyeye Laser Technology Co. Ltd., China. The maximum field angle of the laser generator was $50^{\circ}$, and the laser pulse frequency was $50-550 \mathrm{kHz}$. The point density was a close 15 points per square meter. A digital elevation model (DEM) with a resolution of $0.5 \mathrm{~m}$ was generated by spatial interpolation of ground points after point cloud filtering. During aerial photography, an optical camera with 80 million pixels was mounted coaxially with the laser scanner to generate an orthographic image (DOM) with a resolution of $0.2 \mathrm{~m}$, which was used to assist in landslide identification and interpretation. The spatial reference of DEM and DOM was CGCS2000_102E, and the elevation datum of DEM was the China national elevation datum in 1985. The root mean square error of elevation was less than $0.5 \mathrm{~m}$. The derived DEM helped to generate a number of derived layers that supported landslide identification and characterization. In the current study, a hillside, slope, and sky view factor (SVF) map were derived from the LiDAR-based DEM. LiDAR data processing and LiDAR data products and topographic derivatives were shown in Figure 3.

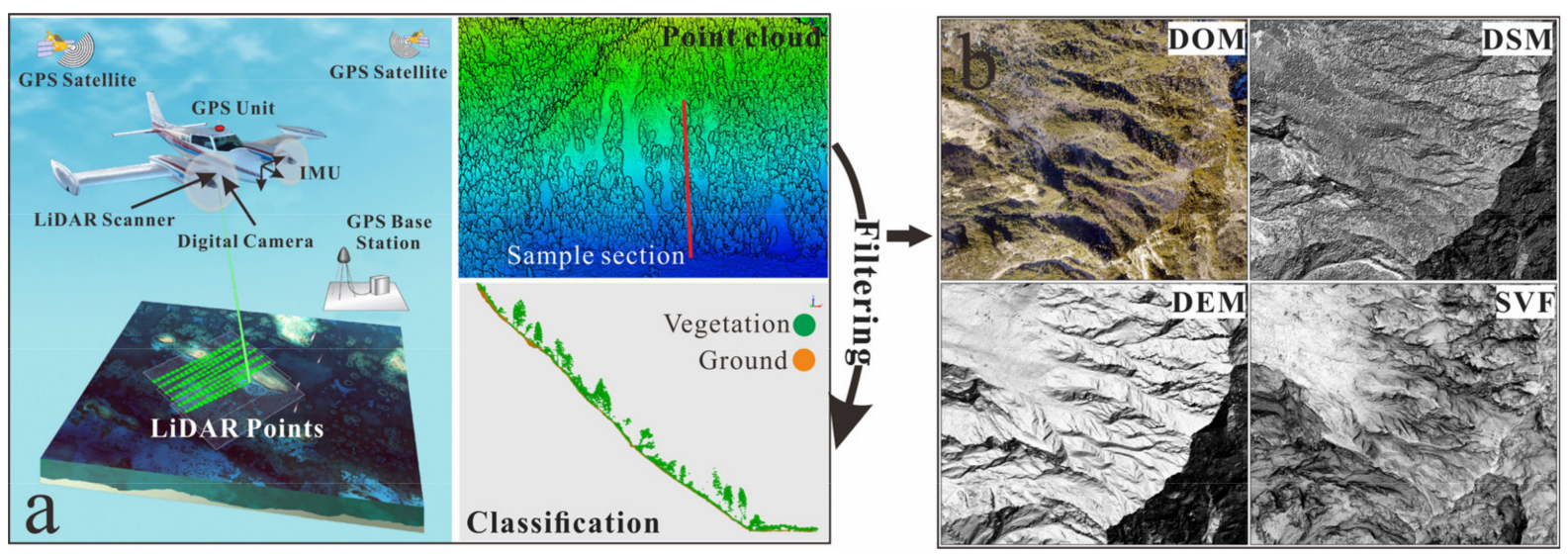

Figure 3. Processing flow and products of airborne LiDAR data. (a) LiDAR pointcloud acquisition and processing; (b) LiDAR products and topographic dervatives.

\section{Results}

\subsection{Active Landslides Mapped by Stacking InSAR}

Figure 4 shows the differential interferograms acquired by stacking InSAR in the study area from October 2014 to September 2020. A total of 44 active landslides with continuous deformation were detected within a range of $540 \mathrm{~km}^{2}$. Among them, 29 landslides were 
detected by the ascending orbit data, 20 were detected by the descending orbit data, and 5 were detected jointly by both the ascending and descending orbit data. All the detected active landslides had a total area of about $59 \mathrm{~km}^{2}$, and they were mostly distributed along the right bank of the Dadu River and its upstream tributary, the Dajinchuan River.

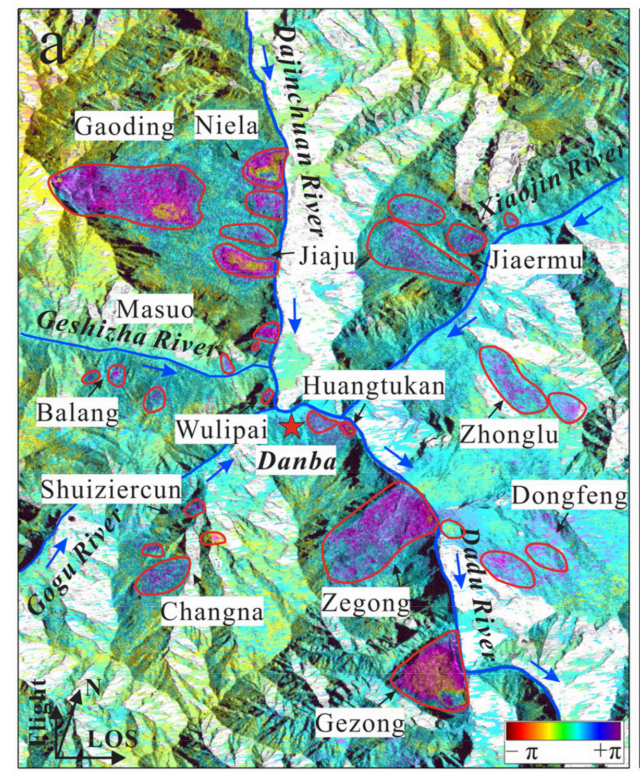

(a)

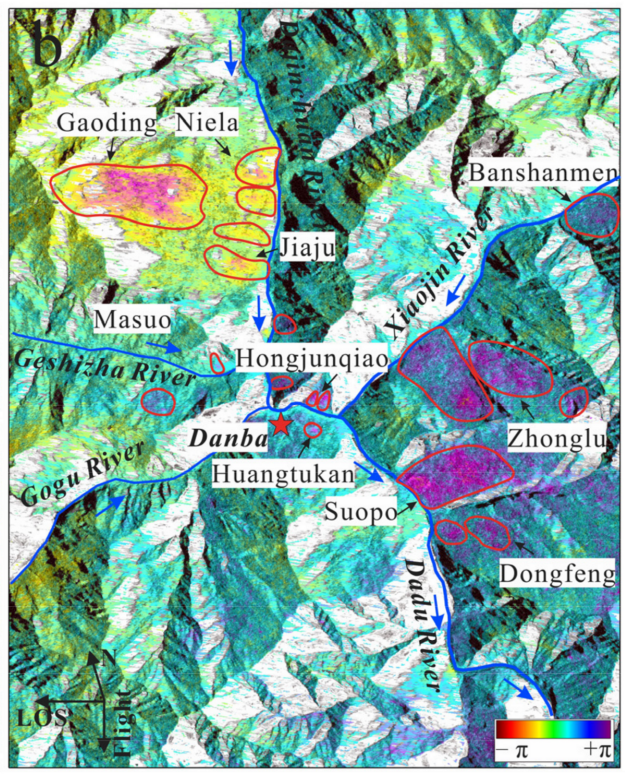

(b)

Figure 4. Geometrically corrected and filtered differential interferograms of the Sentinel-1 stacking InSAR: (a) ascending image pair; (b) descending image pair.

Most landslides near Danba County moved in an east-to-west direction. The ascending orbit Sentinel-1 radar images could be used to detect the potential landslides on the eastfacing slopes. In contrast, west-facing slopes were subjected to influences of shadows, top and bottom inversions, and other geometric distortions in the SAR images. Partial deformation signals from west-facing landslides could be detected in the ascending orbit data. For instance, several landslides, such as Gaoding, Niela, and Jiaju, were located on east-facing slopes, and they could be clearly identified in the ascending orbit data. Meanwhile, there were also certain signals in the descending orbit data. Nonetheless, it was critically necessary to combine ascending and descending orbit data to identify as many potential landslides as possible. However, for south-facing slopes, it seemed that both ascending and descending orbit data detected very few landslides.

\subsection{Landslide Validation Using Airborne LiDAR Data}

More than half of the landslides in the study area were concentrated in densely populated towns in Danba County, such as Jiaju, Wulipai, and Zhonglu towns in the middle-upper parts of the slopes, although there were also some active landslides detected by stacking InSAR along the banks of the river. It was challenging to verify these landslides, because it is difficult to conduct manual ground surveys in such terrain, and also because it is difficult for satellite and optical drone images to show surface features below the vegetation cover. As a countermeasure, this study employed airborne LiDAR data to verify the active landslides detected by InSAR in the above-mentioned major regions $\left(135 \mathrm{~km}^{2}\right)$.

Figure 5 shows the stacking-InSAR-acquired differential interferograms of 10 selected landslides and the SVF images derived from LiDAR-DEM. The landslides detected in the stacking InSAR differential interferograms had a good correspondence in the spatial position with the landslide interpreted from the LiDAR SVF images. However, there were some differences in the landslide boundaries and areas of the same landslide identified by InSAR and LiDAR. In addition, for each location with a large landslide deformation 
rate, there were more obvious traces of motion in the corresponding area on the SVF image, indicating active landslide movement.
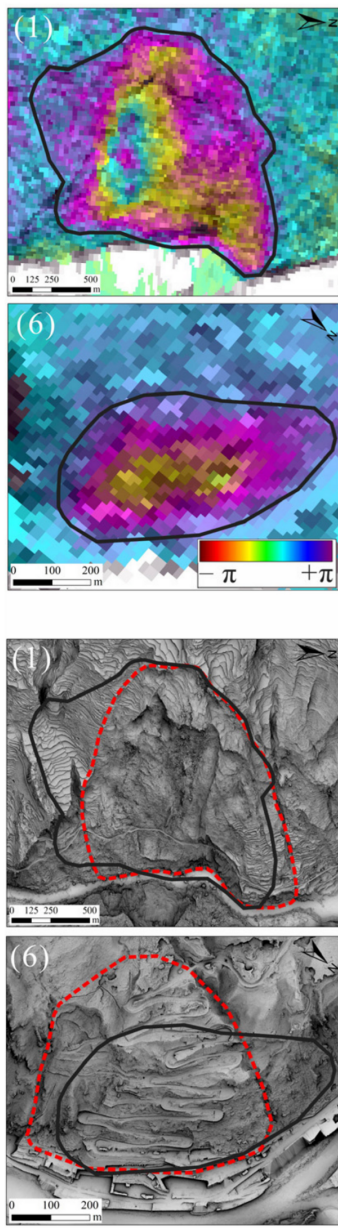

InSAR-based active landslide boundary
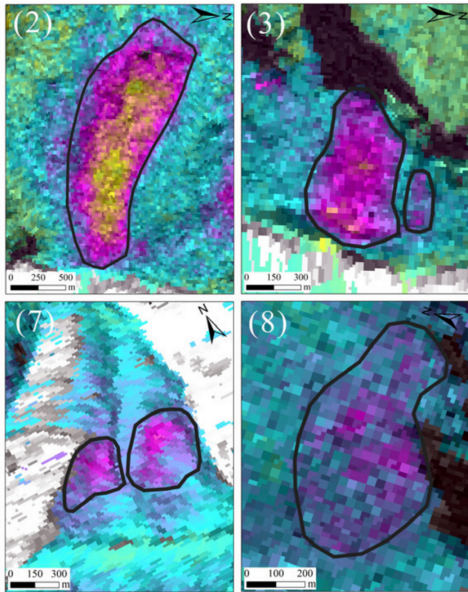

(a)
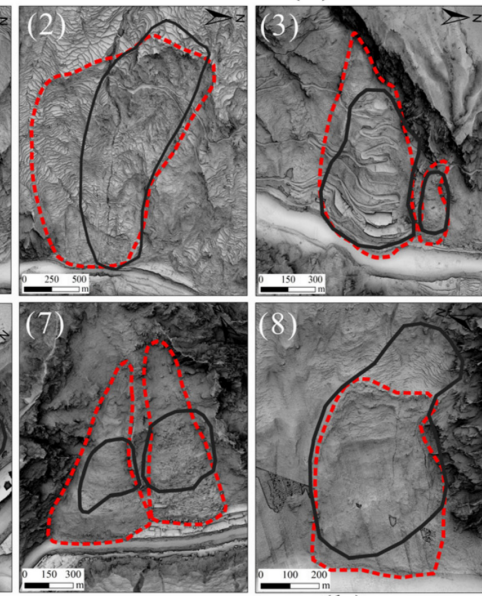

(b)
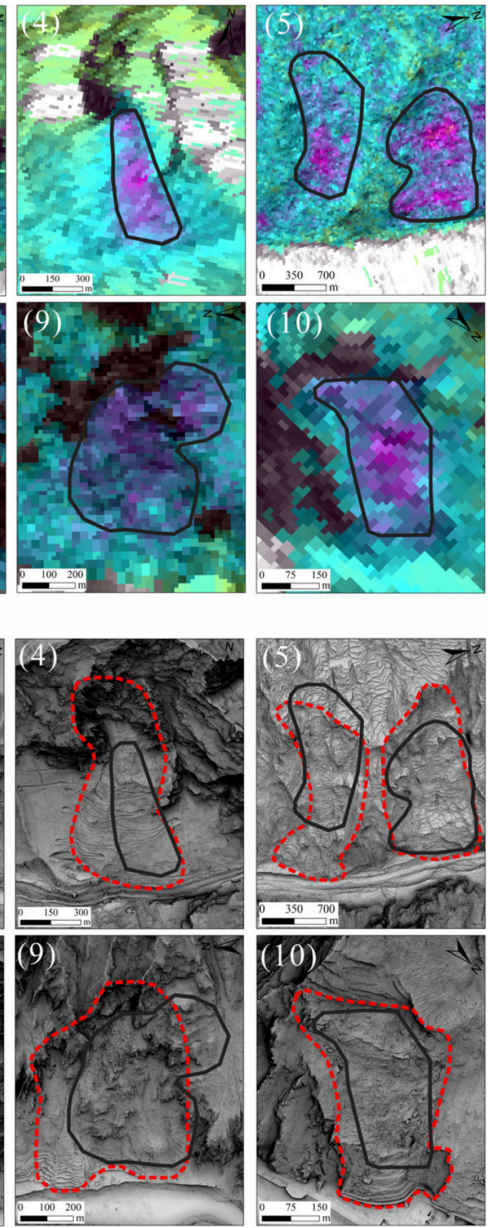

LiDAR-based landslide boundary

Figure 5. (a) Enlarged differential interferograms; and (b) DEM-derived SVF images of 10 exemplary landslides. The black solid lines and the red dotted lines indicate the boundaries of the InSAR-based and LiDAR-based landslides, respectively.

\subsection{Displacements of Selected Giant Landslides by SBAS InSAR}

Three giant landslides were confirmed to have obvious deformation or sliding marks by airborne LiDAR, and they were distributed in the Gaoding area on the right bank of the Dajin River and in Zhonglu Town on the left bank of the Xiaojinchuan River (see Figure 4 for locations). It was crucially important to conduct time-series deformation monitoring for these landslides, because there are potential landslides that can destroy nearby villages, as well as the G248 and G350 national highways at the foot of the slope, thereby threatening people's lives and properties in Danba County and its upstream and downstream areas.

Figure 6 shows the Gaoding landslide in Niega Town, which was about $5.3 \mathrm{~km}$ long and $1.9 \mathrm{~km}$ wide, covering an area of about $10 \mathrm{~km}^{2}$. The elevation difference between the front and rear edges was up to $1940 \mathrm{~m}$. The annual average deformation rate of the Gaoding landslide was as high as $-46 \mathrm{~mm} /$ year (Figure 6a), and there were three main deformation zones on the back, middle, and right-front sides of the landslide. Figure $6 \mathrm{~b}$ shows the SVF image derived from LiDAR-DEM (the red solid line delineates the landslide boundary). The deformation ranges of InSAR-based landslides were found to be in good agreement with those of LiDAR-based ones. Meanwhile, InSAR-based highly deformed areas also presented obvious traces of activity in the LiDAR images. However, these geomorphological features were not easily found in the satellite optical image (Figure 6c). 
Figure $6 \mathrm{~d}$ shows the severely deformed area at the rear edge of the landslide, where there was a small landslide with a height difference of about $165 \mathrm{~m}$ and a length of about $370 \mathrm{~m}$. Additionally, there was a small landslide dam at the toe of the above-mentioned landslide, with a height of about $63 \mathrm{~m}$. Figure 6e shows an area with a large deformation rate in the middle of the landslide, and there were clear traces left by the material movement (indicated by yellow arrows), accompanied by some loose debris. Figure $6 \mathrm{f}$ shows the strongly deformed area on the right side of the front edge of the landslide, and black arrows show the obvious boundary of the local landslide that left traces of sliding on the surface.
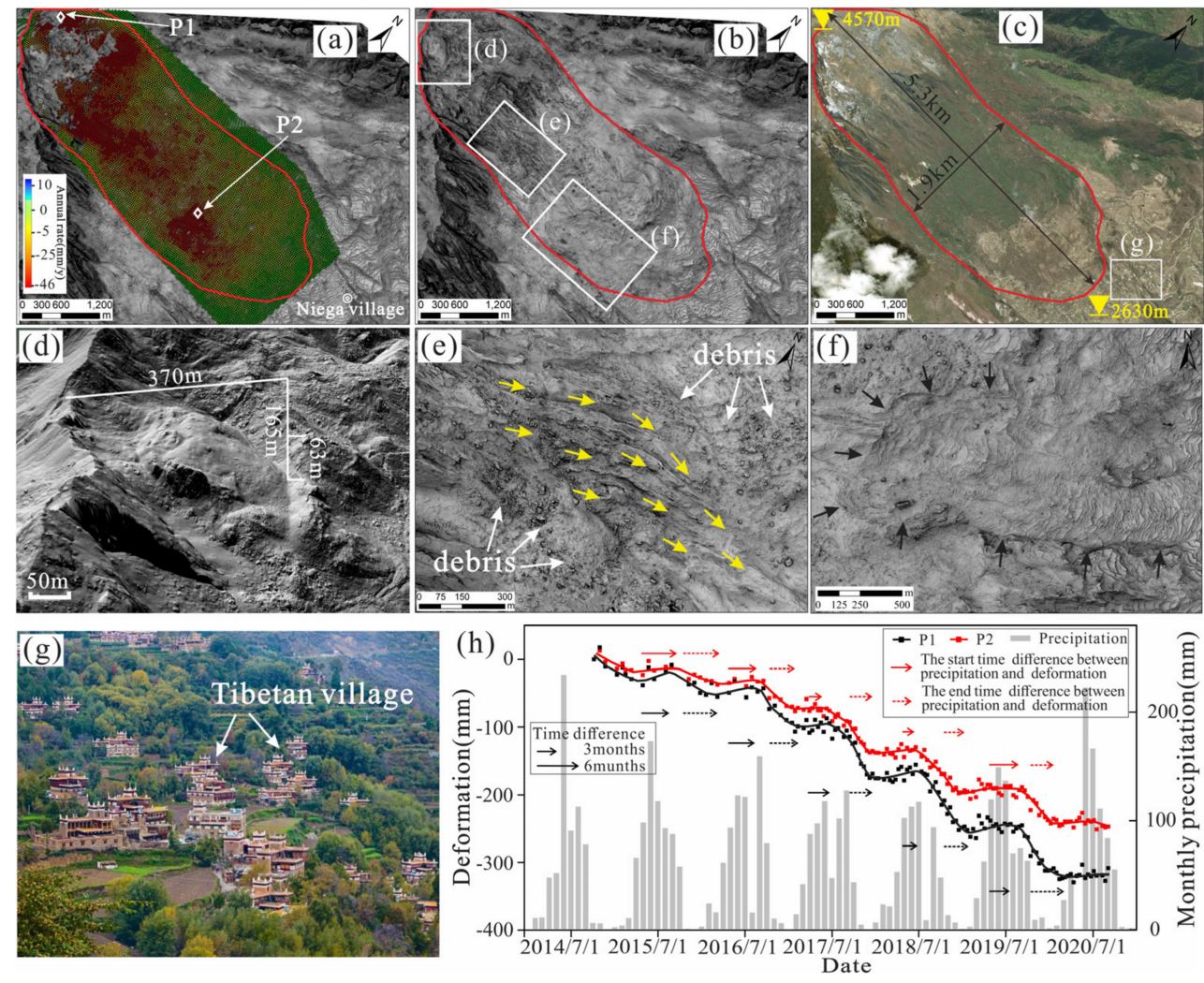

Figure 6. The Gaoding landslide in Niega Town and the relationship between its time-series deformation and rainfall: (a) InSAR-acquired annual average deformation rate of the Gaoding landslide; (b) airborne LiDAR-SVF image; (c) optical image; (d) local landslide at the rear edge of the Gaoding landslide; (e) strong deformation in the middle of the Gaoding landslide, with yellow arrows showing the landslide movement path; (f) a strongly deformed area on the right side of the front edge of the Gaoding landslide, with black arrows indicating the local sliding boundary; (g) Jiaju Tibetan Village; (h) time-series deformation at Points P1 and P2 against monthly precipitation.

Jiaju Tibetan Village is known as the first of the six most beautiful ancient rural towns in China, and it is just below the toe of the landslide, suffering from potential dangers (Figure 6g). Two points (i.e., Points P1 and P2) in the strongly deformed area were selected for time-series-deformation analysis, with consideration of the monthly rainfall data of Danba County (data source: China Meteorological Data Network, http://data.cma.cn/ accessed on 20 December 2020). Landslide deformation was found to be closely related to the monthly precipitation, and it presented obvious features of seasonality. In particular, deformation was obviously accelerated during the rainy season, while it significantly declined and even tended to stop during the dry season. According to the rainfall characteristics of Danba County, the entire year was divided into a rainy season from May to October and a dry season from November to April. The rainfall in the rainy season accounted for more than $80 \%$, and even $90 \%$ in some years, of the total annual rainfall. Subsequently, efforts were made to analyze the relationship between landslide deformation and seasons. 
Obvious hysteretic effects existed between the initiation timing of deformation and that of the rainy season. Similarly, there were also hysteretic effects between the termination timing of deformation and the onset timing of the dry season. As shown in Figure 6h, the black and red solid arrows indicate the time differences between the initiation timing of the rainy season and that of deformation at Points P1 and P2, respectively, which were on average 3.17 and 3.36 months, respectively. The black and red dashed arrows show the time differences between the onset timing of the dry season and the termination timing of deformation at Points P1 and P2, respectively, which were on average 3.62 and 4.08 months, respectively. In general, the initiation of landslide deformation was about 3.23 months after the beginning of the rainy season, while the termination of landslide deformation was a bit longer, about 3.85 months after the end of the rainy season. During the period of October 2014 to September 2020, except for the first and last rainy seasons, the other five rainy seasons corresponded to five complete continuous deformation processes. According to statistics, except for 2015, in the four rainy seasons of 2016-2019, the average annual deformation rate of the landslide during each rainy season was basically positively correlated with the total rainfall of the rainy season and the maximum monthly rainfall. The average annual deformation rates of $\mathrm{P} 1$ and $\mathrm{P} 2$ during each rainy season were about $-110 \sim-125 \mathrm{~mm} /$ year and $-145 \sim-175 \mathrm{~mm} /$ year, respectively.

As shown in Figure 7, Landslides L01 and L02 in Zhonglu Town had deformation areas of $1.12 \mathrm{~km}^{2}$ and $1.24 \mathrm{~km}^{2}$, maximum annual average deformation rates of $-24 \mathrm{~mm} /$ year and $-16 \mathrm{~mm} /$ year, and highest elevations of $4100 \mathrm{~m}$ and $3400 \mathrm{~m}$, respectively. The maximum elevation difference from the river bed was about $2170 \mathrm{~m}$. Specifically, Figure $7 \mathrm{~b}$ shows the topographic features of Landslide L01, where the landslide wall and the frontedge uplift are clearly visible in the high-resolution DEM-derived SVF image. Tensile stress on the rear edge of landslide L02 resulted in fractures that were about $10 \mathrm{~m}$ wide and 5-10 $\mathrm{m}$ deep. There were many obvious secondary ridges formed by smaller sliding on the surface of the slope, accompanied by some small eroded grooves resulting from rain wash (Figure 7c).

Section line A-A' (Figure 7a) was made along the sliding direction of Landslide L01 to further study the relationship between the surface morphology and the deformation rate of the landslide (Figure 7d). The landslide was divided into six zones (i.e., I-VI) according to the deformation rate and topographic characteristics along Line A-A'. Zone I was mainly composed of bedrock with rare deformation. Zone II was the source area of the landslide, where loose rock and soil debris were dominant, and the deformation rate showed an increasing trend year by year. Zone III had the highest deformation rate, with an average of $20 \mathrm{~mm} / \mathrm{y}$. Zone IV featured a decreasing deformation rate, mainly due to the steepened landslide front caused by the obstruction of the terrain. Consequently, obvious wavy squeezed structures were formed on the surface. The landslide deformation rate gradually increased in Zone $\mathrm{V}$, but it turned from a negative value to a positive value, indicating accelerating deformation. Zone $\mathrm{V}$ was the main landslide accumulation area. The landslide deformation rate decreased to zero and tended to be stable in Zone VI, as was represented by the relatively stable bedrock in the topography.

Points P3 and P4 were selected for time-series deformation analysis (Figure 7e). Slow and uniform deformation was observed at Point P3 from October 2014 to October 2017, followed by accelerating deformation from October 2017 onward. Constant slow deformation was seen at Point P4 from October 2014 to September 2020. According to the areas with positive and negative displacements rates observed Figure 7a,e, the landslide L01 could be a rotational landslide. 

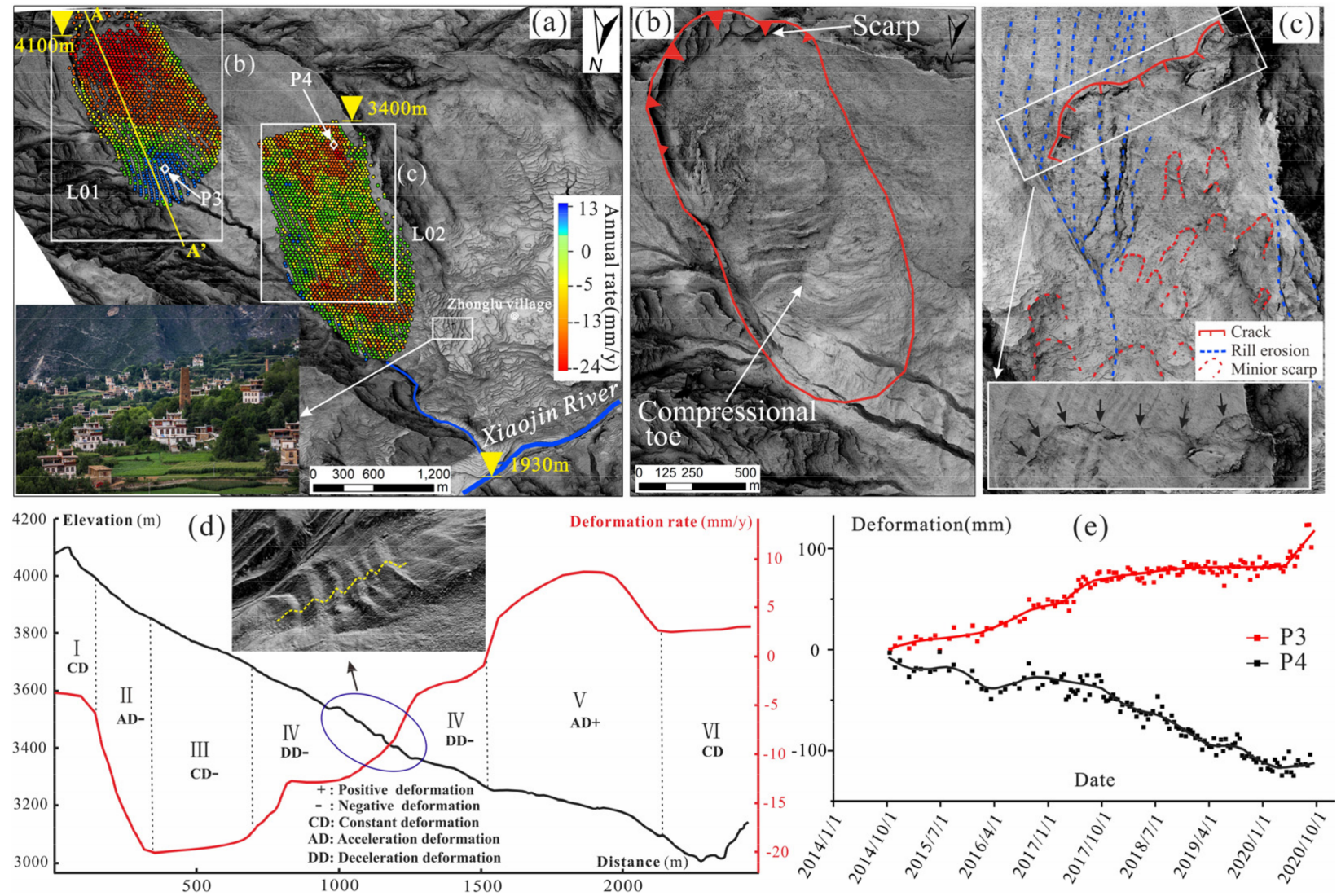

Figure 7. Images of two landslides in Zhonglu Town and the corresponding time-series-deformation analysis: (a) InSARacquired annual average deformation rate of Landslides L01 and L02 in Zhonglu Town (the lower-left corner shows the Zhonglu Tibetan Village under the slope); (b) airborne LiDAR-SVF image of Landslide L01; (c) airborne LiDAR-SVF image of Landslide L02; (d) topographic profile and deformation rate profile along Line A-A'; (e) time-series deformation of Points P3 and P4.

\section{Discussion}

\subsection{Comparison of InSAR-Based and LiDAR-Based Landslides}

As mentioned above, boundaries and areas of the same landslide identified by InSAR and LiDAR were different. In order to quantify the differences, three parameters were proposed, including $\mathrm{A}_{I n}$, which represented the area of the InSAR-based landslide; $\mathrm{A}_{L i}$, which represented the area of the LiDAR-based landslide; and $A_{t}$, which represented the common area between the InSAR-based and LiDAR-based landslides. As shown in Figure 8a, good fitting was seen between $A_{L i}$ and $A_{I n}\left(y=0.843 x-2.041 \times 10^{5} ; \mathrm{R}^{2}=0.844\right)$ as well as between $A_{\text {In }}$ and $A_{L i}\left(y=0.876 x-1.876 \times 10^{5} ; \mathrm{R}^{2}=0.945\right)$.

Then, two derivative parameters were proposed to quantify the matching degree between the landslide identification result and the corresponding technical method, expressed as $M_{L i}$ and $M_{I n}$ for the LiDAR-based and InSAR-based landslides, respectively, In Equations (1) and (2) $[35,36]$, higher $M_{L i}$ and $M_{I n}$ values (ranging from 0 to 1) indicate higher matching degrees.

$$
\begin{aligned}
M_{L i} & =\frac{A_{L i} \cap A_{I n}}{A_{L i}} \\
M_{I n} & =\frac{A_{L i} \cap A_{I n}}{A_{I n}}
\end{aligned}
$$

Among the 36 landslides that were identified in both the InSAR and LiDAR data, the InSAR-based ones had higher $M$ values (median 0.85 and mean 0.70 ) than the LiDAR-based ones (median 0.68 and mean 0.63 ). Moreover, the $M$ values of the InSAR-based landslides 
were relatively concentrated in the vicinity of 0.8 , whereas those of the LiDAR-based ones were more scattered, with a wider range of $0.4-1$.
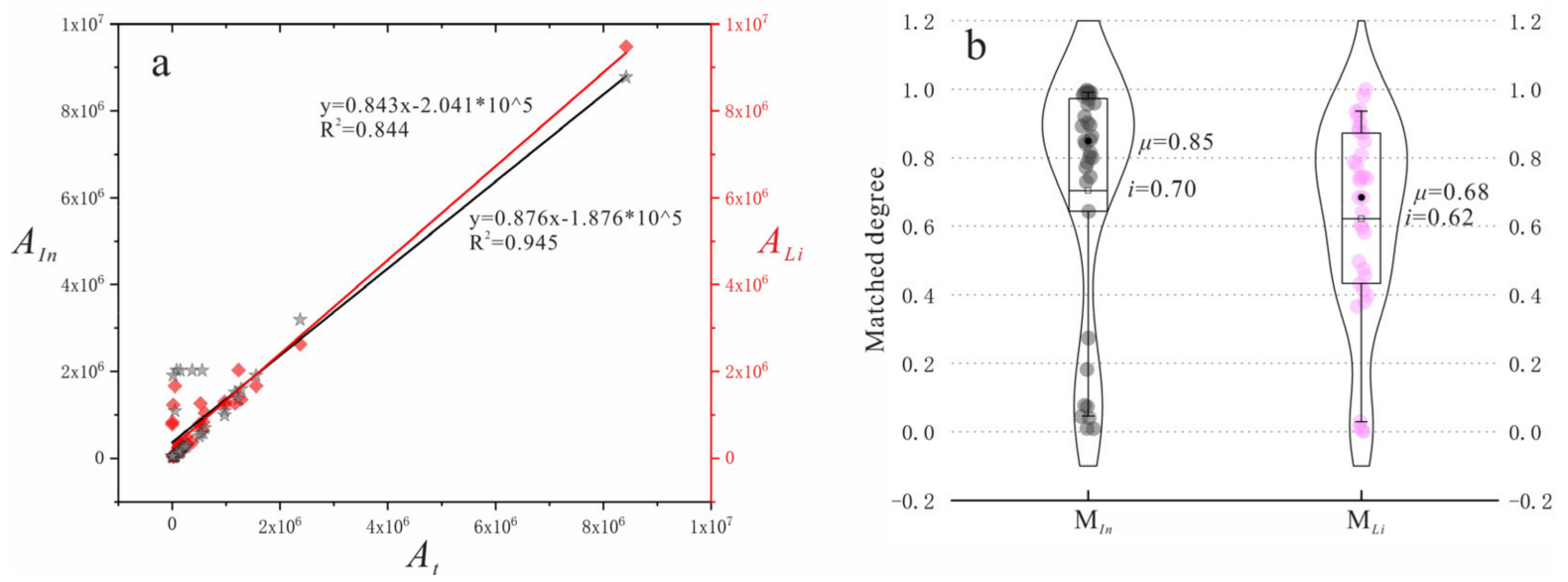

Figure 8. Comparison of InSAR-based and LiDAR-based landslides: (a) relationships between areas of InSAR-based and LiDAR-based landslides and the common area; (b) the matching degrees between the landslide identification results and the corresponding technical methods.

\subsection{Advantages of Combining InSAR and LiDAR Technologies}

Combining InSAR and LiDAR technologies could improve the landslide detection and recognition results, which mainly resulted from the following three aspects.

\subsubsection{Eliminating Slope Deformation Caused by Nonlandslide Activities}

Although InSAR technology could detect millimeter-level deformations on the surface, not all the detected deformation areas were caused by landslide activities. In this context, the employment of LiDAR images could well eliminate the deformations caused by nonlandslide activities. As shown in Figure 9a, the yellow solid line in the differential interferogram marks the main deformation area with the monitoring time of January 2014 to October 2020. However, this area was identified as influenced by a building in the SVF image derived from LiDAR-DEM. Moreover, such influence of building construction was confirmed by the three phases of optical images in October 2015, March 2017, and February 2019, (Figure 9c-e, respectively).

\subsubsection{Identifying Small Landslides and Landslides with Unobvious Deformation}

It is generally difficult to detect and effectively identify some small, deforming landslides in SAR images due to the limitation of the spatial resolution [37]. Moreover, the western mountainous areas in China have steep terrain and dense vegetation, and thus effective interferometric measurement points are relatively sparse, making it difficult to identify small landslides [30]. The red solid lines in the differential interferogram of Figure $9 \mathrm{f}$ delineate the same areas as those landslides identified in the SVF image of Figure $9 \mathrm{~g}$. However, it was almost impossible to infer these two landslides in the differential interferogram (Figure 9f). In contrast, these two landslides were clearly visible in the SVF image. Moreover, these two landslides were seen with obvious signs of deformation within the time range of the InSAR detection during the field survey. An indicative example is the crack on the surface of the highway (built in 2016) passing through the middle of the landslide (Figure $9 \mathrm{~h}, \mathrm{i}$ ), with a length of $20 \mathrm{~m}$, a width of approximately $0.1 \mathrm{~m}$, and a height of approximately $0.15 \mathrm{~m}$. 


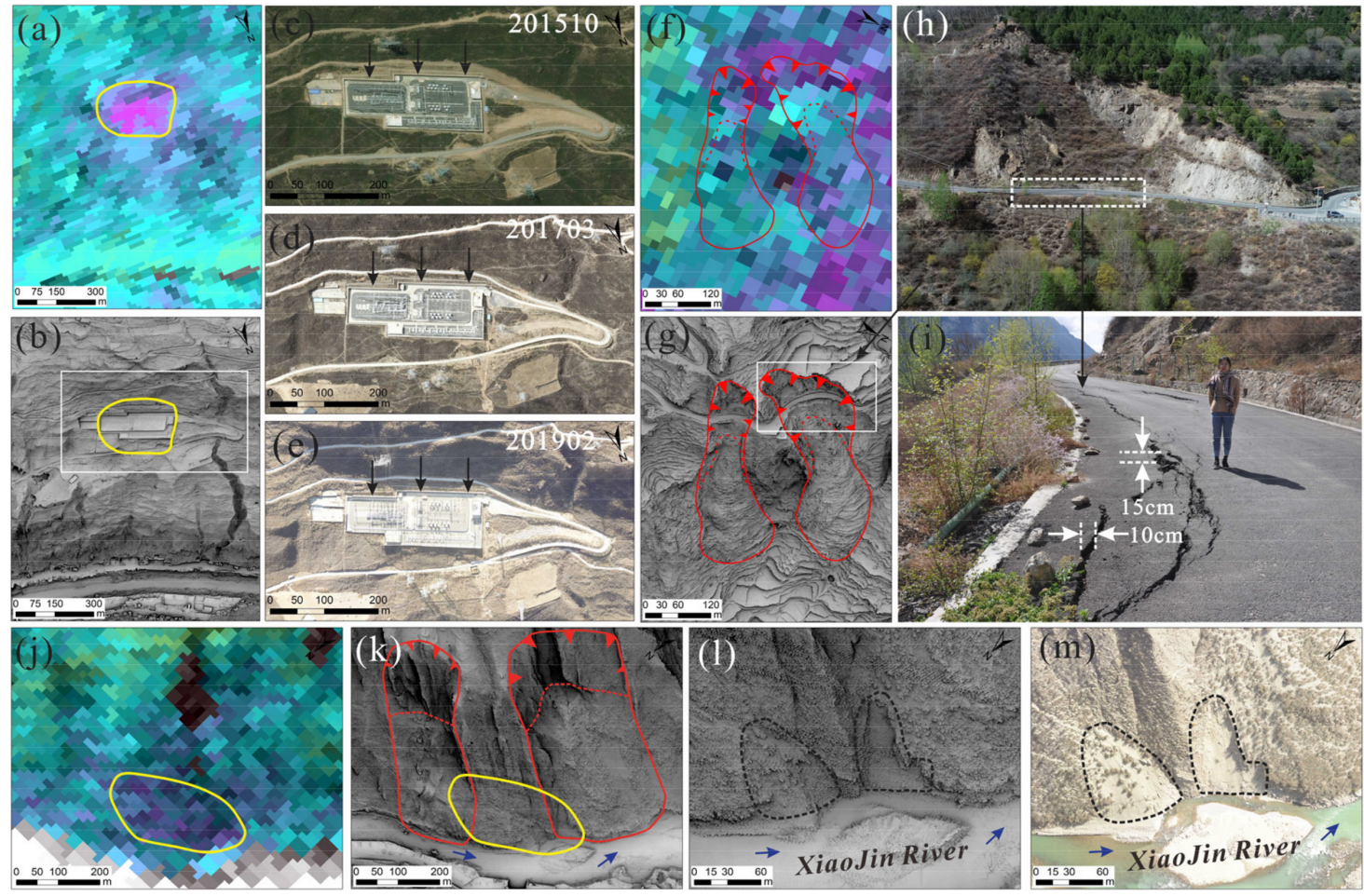

Figure 9. Combination of InSAR and LiDAR technologies to detect landslides: (a) stacking InSAR differential interferogram and the interpreted deformation zone; (b) the corresponding LiDAR-SVF image; (c-e) Optical images corresponding to October 2015, March 2017, and February 2019, respectively; (f) stacking InSAR differential interferogram with suspected landslide boundaries delineated according to those identified in LiDAR images; (g) LiDAR-SVF image and two interpreted landslides; (h) a photo near the landslide area; (i) cracks in the highway caused by landslide activities; (j) stacking InSAR differential interferogram and an area with insignificant deformation; (k) the corresponding SVF image and interpreted landslide boundaries; (1) an enlarged SVF image of the deformed area; (m) an enlarged optical image of the deformed area.

In addition, some areas with insignificant deformation could be detected by InSAR, but they could not be determined as deformed areas, since the slope deformation was insignificant (e.g., the area within the yellow line in Figure 9j). In contrast, two landslides could be obviously observed in the LiDAR image (i.e., the red solid lines in Figure 9k). A zoomed-in view of the slope toe showed obvious sliding deformation (i.e., the black dotted lines in Figure 91,m), which most likely was influenced by the Xiaojin River.

\subsubsection{Accurately Drawing Landslide Boundaries}

InSAR could detect the deforming slope area, but its ability to accurately characterize its boundary was relatively weak [38]. In this context, it was feasible to combine InSAR and LiDAR to more accurately draw the boundary of the landslide, including the secondary boundaries caused by multiple sliding. As shown in Figure 10a, the black line in the differential interferogram of the Zhonglu Town marks the suspected deformation area. Similarly, only two landslides could be identified in the high-resolution optical image (the yellow solid lines in Figure 10b). In contrast, the boundaries of all landslides could be accurately delineated in the LiDAR image (Figure 10c). Moreover, even some small features such as landslide ridges and secondary sliding boundaries could be determined from the LiDAR image (Figure 10d). 


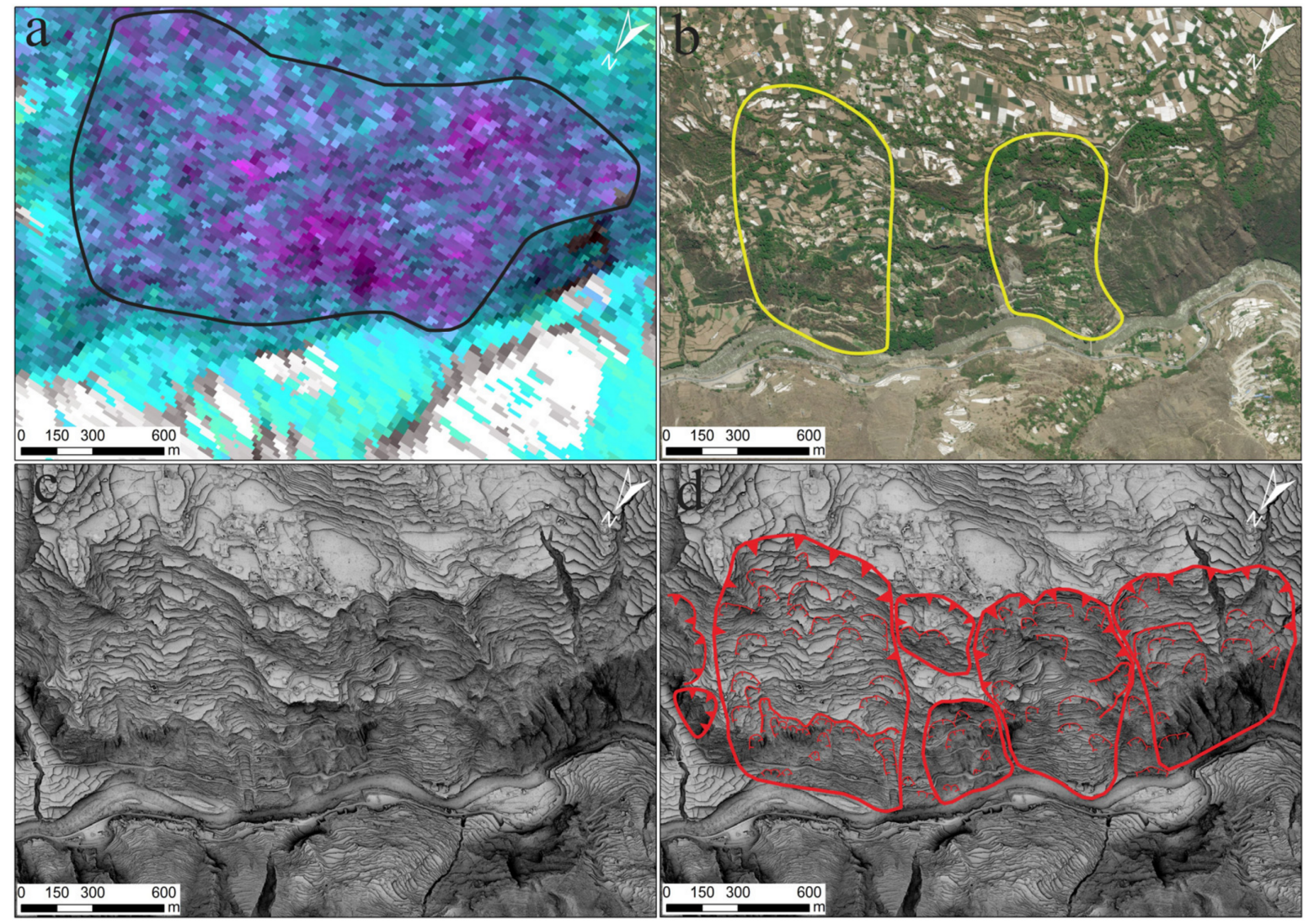

Figure 10. (a) Landslide boundary interpreted in the stacking InSAR differential interferogram; (b) landslide boundary interpreted in the satellite optical image; (c) LiDAR-SVF image; (d) landslide boundaries, ridges, and secondary sliding boundaries interpreted in the LiDAR-SVF image.

\section{Conclusions}

In this study, an integrated method was developed to identify and monitor landslides in densely vegetated and complex mountainous areas. It could detect the surface deformation features by using InSAR technology, while characterizing the micro-geomorphic features by using LiDAR technology. It was successfully applied in Danba County and the surrounding areas in Sichuan Province, China. First, stacking InSAR technology was employed to process 224 Sentinel-1 satellite ascending and descending orbital images, thereby recognizing 44 hidden landslides with continuous deformation in an area of $540 \mathrm{~km}^{2}$. These landslides occupied a total area of $59 \mathrm{~km}^{2}$, and more than half of them were located in densely populated areas around Danba County, severely threatening people's safety, property, and infrastructure. Subsequently, the airborne LiDAR data were used to verify the InSAR identification results in the $135 \mathrm{~km}^{2}$ of major regions. In this way, 33 active landslides were jointly confirmed by LiDAR and InSAR technologies. Three large landslides were found with obvious signs of deformation or sliding, and they were subjected to an SBAS InSAR time-series-deformation analysis. The slope deformation rate was found to be positively correlated with rainfall, with obvious hysteresis effects between the initiation timing of the deformation and that of the rainy season (3.17-3.36 months on average), as well as between the determination timing of the deformation and that of the rainy season (3.62-4.08 months on average). Therefore, it is of critical importance in landslide prevention and early warnings to analyze the slope deformation characteristics and rainfall data.

It was very difficult to classify the landslides only from the deformation characteristics reflected from the interferogram of the stacking InSAR. Even with the validation of LiDAR, it was not particularly easy to classify all landslides in detail based on the geomorphic features. However, for some typical regions or landslides, it was helpful to determine the landslide typology by combining LiDAR high-resolution DEM data and InSAR deforma- 
tion results. So, we are also collecting InSAR and LiDAR results from more areas in order to determine the landslide typology by using morphological and deformation characteristics. In addition, it was helpful to use InSAR results and LiDAR high-resolution DEMs, combined with some advanced algorithms, to invert the landslide thickness and analyze the landslide failure mechanism. The results of this study can provide important guidance for landslide monitoring in the Dadu River Basin of Danba County. In addition, the proposed method is of great value in the identification, prevention, monitoring, and early warning of landslides in vegetation-covered mountainous areas with complex terrain conditions.

Author Contributions: C.G. conceived the manuscript; H.F. and H.L. dealt with InSAR data and drafted the manuscript; C.G. and X.L. dealt with LiDAR data. Q.X. provided funding support and ideas; C.G., X.L. and W.L. conducted a field investigation and provided field data. X.D. and W.L. helped to improve the manuscript. All authors have read and agreed to the published version of the manuscript.

Funding: The work was funded by the National Innovation Research Group Science Fund (No. 41521002) and The National Natural Science Foundation of China (No. 42072306).

Institutional Review Board Statement: Not applicable.

Informed Consent Statement: Not applicable.

Data Availability Statement: Sentinel-1A data used in this study were provided by European Space Agency (ESA) through the Sentinel-1 Scientific Data Hub. Airborne LiDAR data provided by Sichuan Provincial Surveying and Mapping Geographic Information Bureau. Precipitation data China Meteorological Data Network, http:/ / data.cma.cn accessed on 11 December 2020.

Acknowledgments: We are very grateful to sentinel-1A data provided by European Space Agency (ESA), and airborne LiDAR data provided by Sichuan Provincial Surveying and Mapping Geographic Information Bureau. We also thank the reviewers and the editor for their constructive comments and suggestions, which would significantly improve this paper.

Conflicts of Interest: The authors declare no conflict of interest.

\section{References}

1. Huang, R. Some catastrophic landslides since the twentieth century in the southwest of China. Landslides 2009, 6, 69-81. [CrossRef]

2. Xu, Q.; Dong, X.; Li, W. Integrated Space-Air-Ground Early Detection, Monitoring and Warning System for Potential Catastrophic Geohazards. Geomat. Inf. Sci. Wuhan Univ. 2019, 44, 957-966.

3. $\mathrm{Xu}, \mathrm{Q}$. Understanding and Consideration of Related Issues in Early Identification of Potential Geohaz-ards. Geomat. Inf. Sci. Wuhan Univ. 2020, 45, 1651-1659.

4. Fan, X.; Xu, Q.; Scaringi, G.; Dai, L.; Li, W.; Dong, X.; Zhu, X.; Pei, X.; Dai, K.; Havenith, H.-B. Failure mechanism and kinematics of the deadly June 24th 2017 Xinmo landslide, Maoxian, Sichuan, China. Landslides 2017, 14, 2129-2146. [CrossRef]

5. Jia, H.; Chen, F.; Pan, D. Disaster Chain Analysis of Avalanche and Landslide and the River Blocking Dam of the Yarlung Zangbo River in Milin County of Tibet on 17 and 29 October 2018. Int. J. Environ. Res. Public Health 2019, 16, 4707. [CrossRef]

6. Fan, X.; Xu, Q.; Alonso-Rodriguez, A.; Subramanian, S.S.; Li, W.; Zheng, G.; Dong, X.; Huang, R. Successive landsliding and damming of the Jinsha River in eastern Tibet, China: Prime investigation, early warning, and emergency response. Landslides 2019, 16, 1003-1020. [CrossRef]

7. Dong, J.; Zhang, L.; Tang, M.; Liao, M.; Xu, Q.; Gong, J.; Ao, M. Mapping landslide surface displacements with time series SAR interferometry by combining persistent and distributed scatterers: A case study of Jiaju landslide in Danba, China. Remote Sens. Environ. 2018, 205, 180-198. [CrossRef]

8. Li, W.; Xu, Q.; Lu, H.; Dong, X.; Zhu, Y. Tracking the Deformation History of Large-Scale Rocky Landslides and Its Enlightenment. Geomat. Inf. Sci. Wuhan Univ. 2019, 44, 1043-1053.

9. Nichol, J.; Wong, M.S. Detection and interpretation of landslides using satellite images. Land Degrad. Dev. 2005, 16, 243-255. [CrossRef]

10. Roering, J.J.; Mackey, B.H.; Marshall, J.A.; Sweeney, K.E.; Deligne, N.I.; Booth, A.M.; Handwerger, A.L.; Cerovski-Darriau, C. "You are HERE": Connecting the dots with airborne lidar for geomorphic fieldwork. Geomorphology 2013, 200, 172-183. [CrossRef]

11. Görüm, T. Landslide recognition and mapping in a mixed forest environment from airborne LiDAR data. Eng. Geol. 2019, 258, 105155. [CrossRef]

12. Calò, F.; Ardizzone, F.; Castaldo, R.; Lollino, P.; Tizzani, P.; Guzzetti, F.; Lanari, R.; Angeli, M.-G.; Pontoni, F.; Manunta, M. Enhanced landslide investigations through advanced DInSAR techniques: The Ivancich case study, Assisi, Italy. Remote Sens. Environ. 2014, 142, 69-82. [CrossRef] 
13. Intrieri, E.; Raspini, F.; Fumagalli, A.; Lu, P.; Del Conte, S.; Farina, P.; Allievi, J.; Ferretti, A.; Casagli, N. The Maoxian landslide as seen from space: Detecting precursors of failure with Sentinel-1 data. Landslides 2018, 15, 123-133. [CrossRef]

14. Hu, X.; Lu, Z.; Pierson, T.C.; Kramer, R.; George, D.L. Combining InSAR and GPS to Determine Transient Movement and Thickness of a Seasonally Active Low-Gradient Translational Landslide. Geophys. Res. Lett. 2018, 45, 1453-1462. [CrossRef]

15. Fruneau, B.; Achache, J.; Delacourt, C. Observation and modelling of the Saint-Étienne-de-Tinée landslide using SAR interferometry. Tectonophysics 1996, 265, 181-190. [CrossRef]

16. Liao, M.; Tang, J.; Wang, T.; Balz, T.; Zhang, L. Landslide monitoring with high-resolution SAR data in the Three Gorges region. Sci. China Earth Sci. 2012, 55, 590-601. [CrossRef]

17. Hilley, G.E. Dynamics of Slow-Moving Landslides from Permanent Scatterer Analysis. Science 2004, 304, 1952-1955. [CrossRef]

18. Berardino, P.; Fornaro, G.; Lanari, R.; Sansosti, E. A new algorithm for surface deformation monitoring based on small baseline differential SAR interferograms. IEEE Trans. Geosci. Remote Sens. 2002, 40, 2375-2383. [CrossRef]

19. Ferretti, A.; Prati, C.; Rocca, F. Permanent scatterers in SAR interferometry. IEEE Trans. Geosci. Remote Sens. 2001, 39, 8-20. [CrossRef]

20. Zhang, L.; Ding, X.; Lu, Z. Modeling PSInSAR Time Series Without Phase Unwrapping. IEEE Trans. Geosci. Remote Sens. 2011, 49, 547-556. [CrossRef]

21. Ferretti, A.; Fumagalli, A.; Novali, F.; Prati, C.; Rocca, F.; Rucci, A. A New Algorithm for Processing Interferometric Data-Stacks: SqueeSAR. IEEE Trans. Geosci. Remote Sens. 2011, 49, 3460-3470. [CrossRef]

22. Zhang, Y.; Meng, X.; Chen, G.; Qiao, L.; Zeng, R.; Chang, J. Detection of geohazards in the Bailong River Basin using synthetic aperture radar interferometry. Landslides 2016, 13, 1273-1284. [CrossRef]

23. Liu, X.; Zhao, C.; Zhang, Q.; Lu, Z.; Li, Z.; Yang, C.; Zhu, W.; Liu-Zeng, J.; Chen, L.; Liu, C. Integration of Sentinel-1 and ALOS/PALSAR-2 SAR datasets for mapping active landslides along the Jinsha River corridor, China. Eng. Geol. 2021, 284, 106033. [CrossRef]

24. Lu, H.; Li, W.; Xu, Q.; Dong, X.; Dai, C.; Wang, D. Early Detection of Landslides in the Upstream and Downstream Areas of the Baige Landslide, the Jinsha River Based on Optical Remote Sensing and InSAR Technolo-gies. Geomat. Inf. Sci. Wuhan Univ. 2019, $44,1342-1354$

25. Dai, K.; Tie, Y.; Xu, Q.; Fen, Y.; Zhuo, G.; Shi, X. Early identification of potential landslide geohazards in al-pine-canyon terrain based on SAR interferometry—a case study of the middle section of yalong river. J. Radars 2020, 9, 554-568.

26. Liu, X.; Zhao, C.; Zhang, Q.; Peng, J.; Zhu, W.; Lu, Z. Multi-Temporal Loess Landslide Inventory Mapping with C-, X- and L-Band SAR Datasets-A Case Study of Heifangtai Loess Landslides, China. Remote Sens. 2018, 10, 1756. [CrossRef]

27. Lin, C.W.; Tseng, C.M.; Tseng, Y.H.; Fei, L.Y.; Hsieh, Y.C.; Tarolli, P. Recognition of large scale deep-seated landslides in forest areas of Taiwan using high resolution topography. J. Asian Earth Sci. 2013, 62, 389-400. [CrossRef]

28. Guzzetti, F.; Mondini, A.C.; Cardinali, M.; Fiorucci, F.; Santangelo, M.; Chang, K.T. Landslide inventory maps: New tools for an old problem. Earth-Sci. Rev. 2012, 112, 42-66. [CrossRef]

29. Chen, R.F.; Chang, K.J.; Angelier, J.; Chan, Y.C.; Deffontaines, B.; Lee, C.T.; Lin, M.L. Topographical changes revealed by high-resolution airborne LiDAR data: The 1999 Tsaoling landslide induced by the Chi-Chi earthquake. Eng. Geol. 2006, 88, 160-172. [CrossRef]

30. Kang, Y.; Zhao, C.; Zhang, Q.; Lu, Z.; Li, B. Application of InSAR techniques to an analysis of the Guanling landslide. Remote Sens. 2017, 9, 1046. [CrossRef]

31. Zhang, L.; Dai, K.; Deng, J.; Ge, D.; Liang, R.; Li, W.; Xu, Q. Identifying Potential Landslides by Stacking-InSAR in Southwestern China and Its Performance Comparison with SBAS-InSAR. Remote Sens. 2021, 13, 3662. [CrossRef]

32. Van Den Eeckhaut, M.; Poesen, J.; Verstraeten, G.; Vanacker, V.; Nyssen, J.; Moeyersons, J.; van Beek, L.P.H.; Vandekerckhove, L. Use of LIDAR-derived images for mapping old landslides under forest. Earth Surf. Process. Landforms 2007, 32, 754-769. [CrossRef]

33. Glenn, N.F.; Streutker, D.R.; Chadwick, D.J.; Thackray, G.D.; Dorsch, S.J. Analysis of LiDAR-derived topographic information for characterizing and differentiating landslide morphology and activity. Geomorphology 2006, 73, 131-148. [CrossRef]

34. Kasai, M.; Ikeda, M.; Asahina, T.; Fujisawa, K. LiDAR-derived DEM evaluation of deep-seated landslides in a steep and rocky region of Japan. Geomorphology 2009, 113, 57-69. [CrossRef]

35. Carrara, A.; Cardinali, M.; Guzzetti, F. Uncertainty in assessing landslide hazard and risk. ITC J. 1992, $172-183$.

36. Galli, M.; Ardizzone, F.; Cardinali, M.; Guzzetti, F.; Reichenbach, P. Comparing landslide inventory maps. Geomorphology 2008, 94, 268-289. [CrossRef]

37. Li, Z.; Song, C.; Yu, C.; Xiao, R.; Chen, L.; Luo, H.; Dai, K.; Ge, D.; Ding, Y.; Zhang, Y.; et al. Application of Satellite Radar Remote Sensing to Landslide Detection Monitoring: Challenges and Solutions. Geomat. Inf. Sci. Wuhan Univ. 2019, 44, 967-979.

38. Yang, C.Y.; Chi, C.Y.; Chen, R.F.; Lin, C.W. A new and powerful approach to mapping large-scale landslides using InSAR and LiDAR derived DEMs. In Proceedings of the 16th Asian Regional Conference on Soil Mechanics and Geotechnical Engineering, Taipei, Taiwan, 14-18 October 2019. 